\title{
Praças polifônicas: o som e a música popular como tecnologias de comunicação no espaço urbano
}

\section{Polifonic Squares: sound and popular music as comunication tecnologies in the urban spac}

Luiz Henrique Assis Garcia

Doutor em História pela Universidade Federal de Minas Gerais (UFMG). Professor e pesquisador da ECI/UFMG. Membro do Nucleurb CCNM/ UFMG.

<luhen_asgar@yahoo.com.br>

\section{Pedro Silva Marra}

Doutorando pelo Ppgcom da Universidade Federal Fluminense (UFF). Mestre pelo Programa de Ppgcom da Universidade Federal de Minas Gerais (UFMG). É pesquisador do Nucleurb CCNM/ UFMG.

<pedromarra@gmail.com>

\section{RESUMO}

Este artigo tem como objetivo compreender como, através do uso de som e da música popular os habitantes da cidade delineam diferentes práticas para partilhar, disputar e dividir o espaço em duas praças de Belo Horizonte. Para tanto, manipulam sons e seus parâmetros, tais como intensidade, frequência e espacialidade, e mobilizam diferentes repertórios musicais. Tomando a paisagem sonora como uma técnica metodológica que nos permite acessar o som e a prática musical localizada no espaço em sua materialidade, analisamos textos, imagens e sons que registramos para demonstrar como as pessoas dão forma a fronteiras e ambiências sonoras - móveis e transitórias, mas recorrentes - "discotecando" a sonoridade do lugar através de tais tecnologias da comunicação.

\begin{abstract}
This paper aims to understand how, through the use of sounds and popular music the city dwellers outline different practices to share, dispute and divide space at two squares in Belo Horizonte. In order to do so, citizens manipulate sounds and their parameters, such as intensity, frequency and spatiality, and mobilize different musical repertoires. Taking the soundscape as a methodological technique that allows us to access the sound and the musical practices located in space in its materiality, we analyze texts, images and recorded sounds produced by fieldwork to demonstrate how people shape borders and sound ambiences - mobile and transient, but recurrent - "DJing" the sound of the place by such communication technologies.
\end{abstract}

Keywords: Urban space. Soundscape. Communication technologies.

Palavras-chave: Espaço urbano. Paisagem sonora. Tecnologias da comunicação.

As dinâmicas da vida urbana cotidiana produzem uma infinidade de sonoridades condizentes com as diversidades sociais, econômicas e culturais que por aí circulam. Enquanto em uma praça de ocupação mais popular escutamos pregoeiros que anunciam produtos e serviços diferentes, canções 
populares e apresentações de músicos andinos, em outra, de ocupação mais enobrecida, localizada a poucos quilômetros da primeira, músicos de bossa nova começam sua apresentação em palco permanentemente montado na calçada, na frente do café que contratou a apresentação, ao mesmo tempo em que a padaria na esquina toca um disco de pagode, rádio, ou até novelas na TV. Enquanto membros do grupo de pesquisa Nucleurb/CCNM (Núcleo de Estudos Urbanos do Centro de Convergência de Novas Mídias) da Universidade Federal de Minas Gerais (UFMG), investigamos as dinâmicas de conformação do lugar no espaço urbano, sobretudo interessados em como os usos de diferentes mídias convergem para tal fim. Atualmente, o grupo foca seus estudos em quatro praças no centro de Belo Horizonte ${ }^{1}$, uma das maiores cidades do Brasil.

Praças marcam pontos de convergência na tessitura urbana. Sua centralidade cultural, social, econômica e política é demonstrada na vida cotidiana assim como em contextos específicos criados pela vida pública, como celebrações, manifestações populares ou performances musicais. Se as cenas descritas acima parecem confirmar o que é repetido usualmente em pesquisas acerca da questão do som no espaço urbano, uma tese que coloca que a sonoridade muito intensa e "povoada" da cidade aponta para uma escuta distraída e desatenta ao ambiente sônico, uma escuta mais próxima destes contextos mostra que não só "a floresta equatorial demanda e favorece habilidades perceptuais de audição agudas" a partir das quais as pessoas "desenvolvem um tipo de estrutura ideológica e estética para estas habilidades que os humanizam e fornecem um quadro cultural coerente para sua aquisição" 2 (Feld, 1984, p. 389).

Este trabalho investiga duas praças, Sete de Setembro, e Diogo de Vasconcelos, mais conhecidas respectivamente como Praça Sete e Praça da Savassi. Ao reconhecermos que os espaços públicos constituem-se por todos os tipos de conflitos e negociações, devemos ter em conta a multiplicidade de atores sociais e sua performance na arena pública, a fim de compreender

1 O projeto "Re-encontrar o Público nas praças da cidade: novas formas de apropriação no espaço urbano em transformação na Belo Horizonte do século XXI"recebeu apoio do CNPq. Versões preliminares desse artigo foram apresentadas anteriormente no XI Congresso da IASPM-AL (Salvador, 2014) e no Simpósio Invisible Places, Sounding Cities, (Viseu, Portugal, 2014), neste caso já publicada em inglês. Agradecemos as considerações recebidas dos colegas em ambos.

2 As traduções de citações em língua estrangeira são de nossa autoria. 
como eles transformam o espaço em lugar, como localizam (Appadurai, 1996) suas identidades. Seus confrontos e acomodações não só modificam o espaço urbano, mas também são modificadas pelas mudanças que historicamente acontecem nele.

Nestes processos de conformação urbana os sons são muitas vezes utilizados como tecnologias sensíveis por parte dos habitantes da cidade. Gritos, sons altos ou suaves, música, posicionamento dos alto-falantes, "produzem as texturas estéticas de ocasiões, situações e estilos de ação sociais" (DeNora, 2004, p.111), conformando um repertório (Faulkner; Becker, 2009), através do qual diferentes agentes - cada um apresentando diversas potências e durações - em suas ações nas ruas, compartilham, disputam ou conquistam a propriedade do espaço público. Nosso trabalho de campo aplica diferentes formas de registrar (gravações de áudio, relatos escritos, fotos e vídeos digitais) tais usos do espaço realizadas durante derivas pelas praças. Tomando a paisagem sonora (Schafer, 2001) como técnica metodológica que nos permite acessar o som e a música localizados no espaço, discutimos as formas com que cidadãos manipulam suas propriedades acústicas (intensidade, frequência e espacialidade) e diferentes repertórios musicais para produzir o "lugar". Nestes processos, os agentes dão forma a fronteiras e ambiências sonoras - móveis e transitórias - mas recorrentes. Desta forma, nossa investigação tem a intenção de capturar e analisar os processos acima delimitados, por meio de uma perspectiva comparativa.

\section{Som e lugar: disputando, compartilhado e dividind o o espaço}

Apesar de o som ser constantemente associado à duração e à constituição de temporalidades, a espacialidade também é uma característica importante das sonoridades. O fenomenólogo Don Ihde (2007), a partir da exploração das possibilidades de escuta de formas, superfícies e interiores por meio de um foco a propriedades do som, tais como a continuidade/descontinuidade da sonoridade de um corpo que rola, o timbre produzido pelo esfregar de dois objetos, os efeitos de reverberação e eco, mostra que se a característica primária do mundo audível é temporal, uma outra característica mais fraca, mas importante são suas propriedades espaciais. Sua discussão evidencia como estas espacialidades são escutadas por meio de variações temporais, mostrando que "mesmo a divisão 
do espaço e tempo não são, estritamente falando, significações primitivas da experiência" (Ihde, 2007, p. 61).

A interação entre temporalidade e espacialidade é fundamental para o entendimento do lugar como espaço usado, como diversos autores já demonstraram (Tuan, 1983; Certeau, 1994; Santos, 1996)3. Por meio de práticas sociais variáveis dependendo das horas do dia, estações do ano, entre outros intervalos de tempo; os cidadãos inscrevem sentidos no espaço urbano, usando seus componentes materiais, como a característica das calçadas, a presença de bancos para sentar e de edifícios, etc. A cidade é também o lugar onde diversidades se encontram e disputam seu uso e significado, o que traz a frente sua dimensão de espaço apropriado e dominado, evidenciado na noção de território (Haesbaert; Limonad, 2007, p. 2). Portanto, se o espaço aparece como construção social (Low, 1999, p. 111), sua materialidade, percebida historicamente, afeta e é afetada por relações sociais de natureza diversa, incluindo aí as formas de sociabilidade e processos comunicativos. Traçar a trama da cidade, percebendo as transformações de seus espaços materializadas nas mudanças de sua fisionomia, nas substituições dos objetos e pessoas que os ocupam, se faz necessário para compreender as interações entre sujeitos nestes lugares, mesmo aquelas mediadas pelos objetos tecnológicos da comunicação.

Investigar estas questões envolve atenção às operações realizadas pelos habitantes no espaço da cidade, o que confere às suas idas e vindas cotidianas caráter performativo. Como andam nas calçadas? Onde atravessam as ruas? Somente se senta nos bancos das praças? Com quem se conversa e quem se evita no ponto de ônibus? Todas estas dinâmicas requerem movimento e, portanto produzem som, um dos meios nos quais tais processos tornam-se presentes, são tocados pelos corpos dos transeuntes, evidenciando que "a maneira como nos relacionamos com estes lugares é baseada na experiência sensória que fornecem" (Thibaud, 2011, p.1). Assim, neste "espaço-tempo vivido" (Haesbaert, 2006) não só "a materialidade sonora opera como 'micro-epistemologias', com o eco, a vibração, o rítmico, por exemplo, abrindo-se para formas específicas de conhecimento do mundo" (Labelle, 2010, p. XXV), mas também apresenta todo um esquema de ação no mundo, já que entendemos o som, apoiados em Wisnik

3 Certeau (1999) inverte a relação entre estes dois termos, entendendo espaço como lugar usado. 
(1989), como a comunicação de um sinal de movimento em um ambiente, como corpo que ressoa em outro. E ao fazê-lo, "o som se torna presença, e nesta presença, se torna uma parte essencial da infraestrutura de um prédio [ou de um lugar]" (Sterne, 1997, p. 23). As sonoridades se mostram, portanto, tecnologias sensíveis, formas disponíveis aos sujeitos para afetar e ser afetado (Thompson; Biddle, 2013).

Tia DeNora mapeia formas como os sujeitos usam música para realizar certas tarefas. Ela estuda como música rápida ou lenta é manipulada em uma festa onde o anfitrião deseja que seus convidados dancem ou conversem, ou como lojas usam música ambiente como "meio de delinear o território de compras, uma forma de projetar o imaginário dos consumidores no espaço configurado esteticamente da loja" (DeNora, 2004, p.135). Neste sentido, aponta para o uso da música na construção de uma ambiência, "um espaço-tempo qualificado de um ponto de vista sensório. [...] um humor específico expresso na presença material das coisas e corporificado na forma como se é um habitante da cidade". (Thibaud, 2011, p.1-2).

A argumentação de DeNora baseia-se na noção de affordance. Se por um lado o material sonoro manipulado na música traz certas possibilidades, privilegiando certos usos ao invés de outros; por outro a música não realiza trabalho por si só, é necessário agência de seus usuários, para que possa produzir aquilo para o que foi planejada, ou até para produzir um efeito contraditório. Assim, articulamos as ideias da autora com os estudos de Faulkner e Becker, que descrevem como diferentes contextos onde a música jazz é performada requerem não só diferentes repertórios musicais, ou listas de canções, mas também diferentes técnicas para tocar estas composições.

Em seu relato etnográfico, os sociólogos nos contam como, em um hotel norte-americano na Nova Inglaterra, "a sala confortável de sensação rústica, com chão de carvalho e nogueira, com um grande carpete oriental apresenta um som quente" (Faulkner; Becker, 2009, p. 10). Eles também mencionam a apreensão do dono do local com os níveis sonoros (intensidade) que um trompetista poderia produzir, incomodando seus clientes na sala de jantar. Em sua proposta de entender o repertório em ação, da forma como seus usuários o praticam, eles tentam taquigrafar elementos sonoros envolvidos na produção 
da música, como um evento, que congrega "uma lista de músicas possíveis, perguntado a outro músico o que ele deseja tocar, decidindo (antes ou durante a performance) o que tocar e quando" (Faulkner; Becker, 2009, p. 194). Um desses elementos são as situações de performance nas quais os músicos estão, que delineiam o que o público espera escutar - o conjunto de canções e como serão performadas - com o objetivo de fazer a música em certo contexto acontecer: canções sincopadas e bandas intensas em salões amplos convidam a dança; temas melódicos e suaves em salas de jantar acanhadas, mas agradáveis favorecem a conversa.

Assim, Faulkner e Becker preocupam-se em entender a maneira idiossincrática dos músicos constituírem seus repertórios, diversos e dinâmicos, os transformando quando se encontram, pois constituição de um repertório intercambiável é imperativa já que os músicos precisam tocar uns com os outros. Ao considerar diferentes situações de trabalho, eles identificam no contexto uma dimensão inescapável para entender o que é sacado de um acervo composto por milhares de canções populares produzidas no âmbito da indústria, além de canções étnicas e tradicionais. Extrapolando um pouco em relação aos autores, podemos considerar que mesmo no caso da execução de música gravada poderemos identificar um repertório constituído de forma a atrair e fixar os clientes pretendidos, e, simultaneamente, afastar os que não se enquadrem no perfil desejado.

A aproximação dos trabalhos de DeNora e de Faulkner e Becker abrem, portanto, caminho para que possamos entender como os habitantes da cidade usam o som a fim de ocupar o espaço, seja na sua disputa, compartilhamento ou divisão. Nestas tarefas, os cidadãos usam não só certos sons, mas os manipulam por meio do cruzamento de suas propriedades acústicas, como intensidade, frequência e espacialidade. Em artigo sobre o Jazz na cidade de Nova Orleans, Sakakeeny nos conta como "Buddy Bolden [...] apontava seu trompete para o céu e o assoprava alto e 'quente' seduzindo o público a deixar as proximidades do Parque Lincoln" (Sakakeeny, 2006, p. 41), onde outros músicos tocavam um tipo de música diferente. Neste exemplo, o jazzista manipula a direcionalidade e a intensidade do timbre de seu instrumento de sopro a fim de realizar um chamado. Adiante em seu artigo, o autor relata como, durante o MardiGras, 
bandas de metais respondem à passagem do desfile Zulu por baixo de uma ponte"soprando seus instrumentos o mais forte o possível, o som adernando na infraestrutura de concreto" (Sakakeeny, 2006, p. 43). Ao fazê-lo, eles manipulam a intensidade e reverberação produzido por um lugar específico para desafiar a exclusão social, pois o mencionado viaduto foi construído em 1960 a fim de segregar uma área africana da cidade.

De forma similar, acreditamos que algumas propriedades acústicas do som são manipuladas pelos sujeitos, na maioria das vezes, a fim de realizar certa apropriação e dominação do espaço. Disputá-lo é a tônica quando o principal parâmetro é a intensidade - a urgência de fazer sons intensos é a necessidade de silenciar oponentes. A frequência (tanto em termos de melodias, ritmos e timbres, quanto em termos do período no qual a repetição ocorre, ou até mesmo duração) é mais usada quando se deseja compartilhar o espaço. Nestas dinâmicas, os corpos são potencialmente arrastados a sincronizar-se, imprimindo "um ritmo em uma era, seja pela força ou de maneira insinuante" (Lefebvre, 2004, p. 25) por meio do qual se realizam transformações sociais. Como resultado, os sons produzidos no espaço compartilhado acomodam-se uns aos outros. Já a espacialidade refere-se a procedimentos como o arranjo da posição das fontes sonoras, ou a fenômenos como a reverberação no espaço, e a direção de um som. É usualmente acessada quando a intenção é a de lotear o espaço, inserindo no lugar uma fronteira, às vezes efêmera, que institui onde certo território começa e termina - a manipulação destas propriedades torna possível controlar o alcance de certo som. Não estamos argumentando com isso que estes parâmetros são usados somente para tais tarefas, mas que eles viabilizam tais usos que são virtuais e precisam ser realizados pelos usuários de maneira bem-sucedida, o que retoma a dimensão performativa da produção do lugar, já discutida neste artigo. $O$ que se delineia aqui representa algumas linhas guia que podem mudar de acordo com a situação, com as formas como os sujeitos os acessam e com outros parâmetros que também estão em jogo.

\section{Compartilhando e disputando a Praça Sete}

A Praça Sete de Setembro, também conhecida como Praça Sete, é uma das principais áreas de interesse da cidade e é um ótimo exemplo de certa 
tradição urbana moderna, que oferece a cidade apenas para aqueles poucos que usufruem dos direitos de cidadania (Maricato, 2000). Estima-se que todo dia, cerca de dez mil pessoas circulam por suas ruas e calçadas durante o horário de pico (de duas às três e quinze da tarde), já que se configura como a principal articuladora do trânsito da cidade. No natal, estima-se que 800 mil pessoas por dia circulam por esse lugar. O espaço também abriga sedes de bancos e repartições públicas responsáveis pela emissão de documentos como carteiras de identidade e passaportes. Várias atividades comerciais e recreativas, como comércio e serviços ambulantes, assim como apresentações artísticas e circenses, por exemplo, podem ser encontradas na Praça Sete. A praça também é conhecida como local onde criminosos adquirem armas ilegais e documentos falsos.

Durante 2003 e 2004 a praça foi reformada sob o argumento de que era um lugar morto, apesar de atrair grande quantidade de pessoas todos os dias. A fim de implementar políticas de marginalização, uma série de notícias depreciativas foi publicada em jornais e transmitida pela mídia, logo antes das obras começarem, reforçando o imaginário de criminalidade, uso de drogas e prostituição já presente coletivamente entre os habitantes. Esta campanha midiática atuou a favor da reforma urbana que construiu ou reformou quatro calçadões ${ }^{4}$ que expulsaram os camelôs que ali trabalhavam. Apesar da instituição de políticas de enobrecimento do espaço ligadas a fluxos globais de capital especulativo-imobiliário, uma série de práticas diversas - marcadamente ligadas a agentes de menor poder econômico - continuam ocupando o lugar (figura 1$)^{5}$.

4 Cada quarteirão fechado foi pensado de acordo com diferentes projetos arquitetônicos e nomeado com a designação de uma das quatro tribos indígenas de Minas Gerais, o estado do qual Belo Horizonte é a Capital: Maxakali, Krenak, Xacriabá e Pataxó.

5 As localizações das práticas aqui relatadas nos mapas das figuras 1 e 4 remetem a sua posição no momento em que foram captadas pela pesquisa. Como argumentamos no artigo, tais localizações podem mudar de acordo com o tempo, sobretudo aquelas de caráter mais popular e informal. 
- Fig. 1: Mapa síntese da ocupação da Praça Sete.

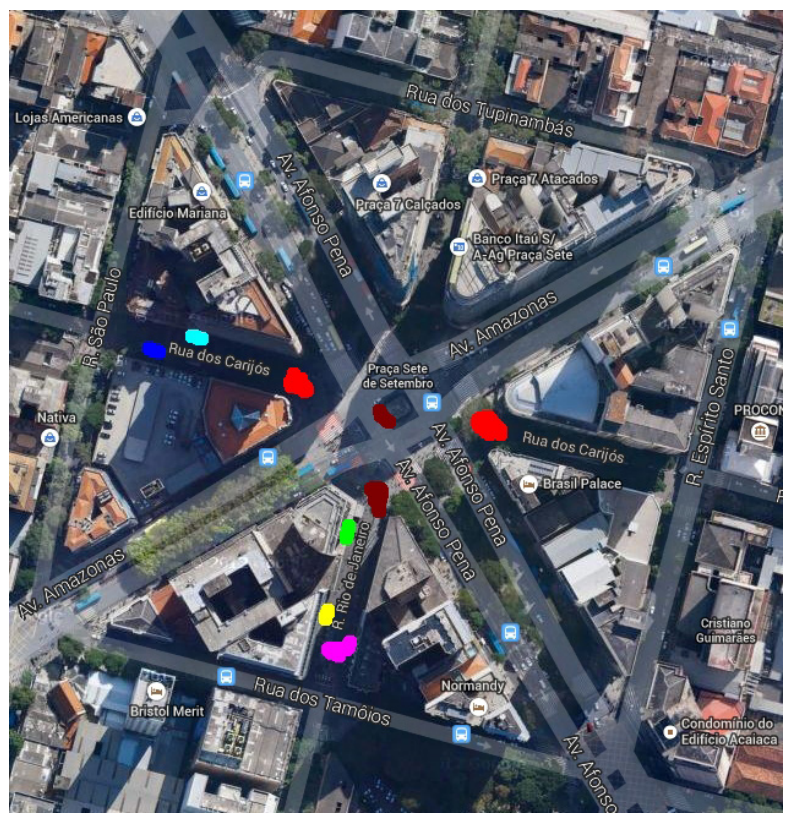

Vermelho: Área de shows populares

- Azul Escuro: Dormitório Sem Teto

- Azul Claro: Loja de discos

Verde: Galeria do Rock

Amarelo: Região ocupada por skatistas

Marrom: Locais de manifestações

- Rosa: Bar com música ao vivo

Fonte: Mapa extraído do Google Maps e alterado digitalmente pela pesquisa, 29/05/2014.

Discutimos em outro artigo (Franco; Marra, 2011) como pregoeiros podem ser escutados como indicadores sonoros dos níveis de ruído e fluxo de carros e pedestres nas ruas. No centro de Belo Horizonte, descobrimos que quanto mais longo e intenso for o pregão, mais intenso será o fluxo de carros e menor o fluxo de pedestres. Na Praça Sete, com seus quatro calçadões, existem pregoeiros anunciando lojas de telefone celular e serviços como corte de cabelo e fotografia $3 \times 4$. Eles se sincronizam com o grande fluxo de pedestres e um pequeno número de carros no meio do quarteirão, emitindo seus anúncios em um ritmo rápido e não tão intenso. De acordo com o período do ano, eles também espalham sua ocupação para as calçadas próximas ao cruzamento de duas avenidas até as esquinas a um quarteirão de distancia do centro da praça (figura 1).

De vez em quando, um professor de matemática é encontrado no 
meio dos pregoeiros, lecionando aulas informais sobre a solução rápida de problemas da matéria. Ele usa um microfone acoplado a fone de ouvido, ligado em pequenas caixas de som a pilha que amplificam sua fala, e que também impõem um timbre metálico a sua voz. Enquanto fala continuamente, por cerca de 15 minutos, ele discorre sobre conteúdos como raiz quadrada, matemática financeira, e assim por diante, em um quadro branco portátil que carrega consigo. Os passantes param a seu redor e eventualmente compram os DVDs que ele vende com suas lições, organizadas por matérias, que ele acabou de ensinar. Enquanto o professor fala, os pregoeiros mantêm seus gritos ritmados. Uma estranha forma de colaboração se estabelece entre estas duas categorias de trabalhadores informais. De vez em quando, outra pessoa chega à praça trazendo lanches e bebidas para descansar suas vozes. Apesar de informal, ambos os tipos de trabalho na verdade mostram uma estrutura frouxa, já que o professor também é auxiliado por sua esposa, que traz a ele novos DVDs toda vez que ele interrompe o trabalho para descansar.

Se os pregoeiros e o professor de matemática parecem em um primeiro momento competir entre si, eles de fato compartilham o espaço acústico da praça, para que todos sejam escutados em sua ambiência ruidosa. Para tanto, manipulam a intensidade das emissões - nenhum deles soa intenso - mas também a frequência - as ocorrências sonoras em determinado período - já que os pregoeiros evitam gritar ao mesmo tempo e o professor de matemática faz intervalos, não só para descansar, mas também para conversar com os clientes que param. Esta "vadiagem" dos pedestres em torno das aulas também ajuda os pregoeiros, que veem crescer suas chances de ser escutados.

A Praça Sete também é palco usual para grande número de shows populares realizados por indígenas brasileiros e populações andinas que se revezam na sua ocupação. Ambos os grupos montam seus equipamentos de som portáteis nas calçadas e executam suas músicas - os andinos usualmente tocam canções pop globais em suas flautas de bambu, os índios brasileiros tocam algo que soa como uma mistura de música popular e indígena. Embora executem uma música à primeira audição desterritorializada, inscrevem na praça um lugar para execução de apresentações em geral. Enquanto um grupo desmonta, o outro prepara sua apresentação, em agenda imprevisível, pois 
um grupo ou outro abre a sessão, ou arranjam suas apresentações em dois calçadões diferentes da praça. Os indígenas brasileiros também utilizam o lugar como feira, onde vendem artesanato, como colheres e recipientes de madeira, colares, brincos, etc. (figura 2). O local é também compartilhado por números circenses e desafios, como performances acrobáticas e de palhaços. Todas estas pessoas usam sua voz para anunciar seu trabalho.

Fig. 2: Exposição de artesanato Indígena, 11 de novembro de 2013.

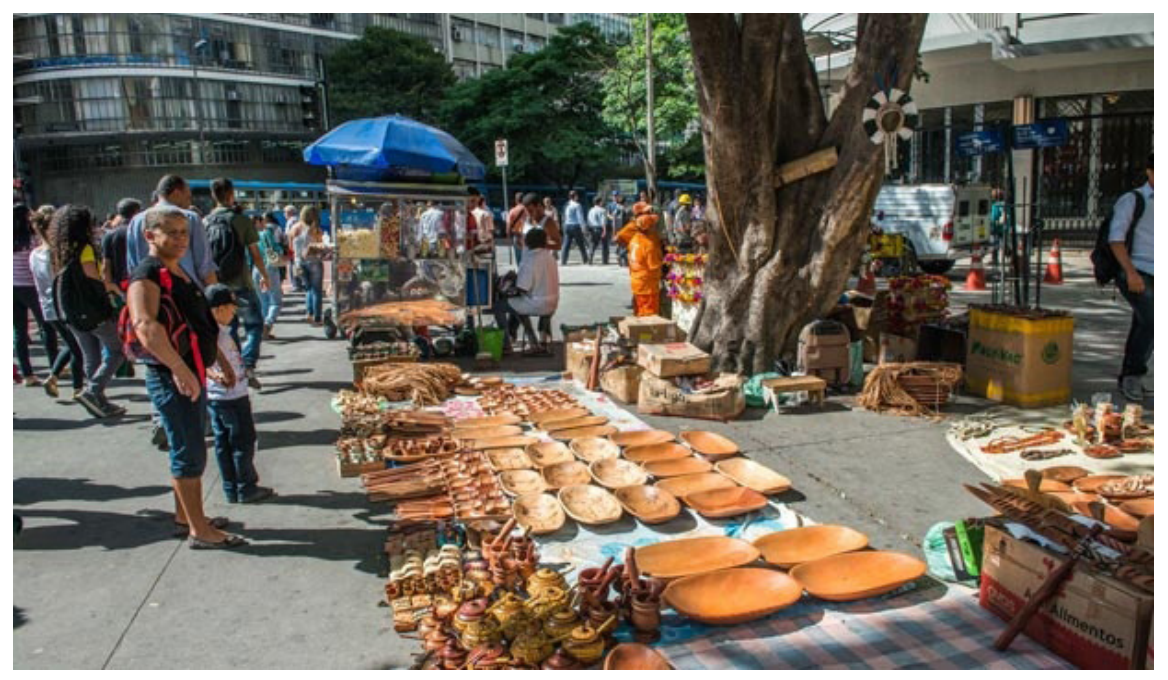

Foto: Maíra Oliveira.

Assim, as sonoridades produzidas soam como o "lifting-up-over" que Feld (1984) encontrou entre os Kaluli. Neste estilo de cantar, "mesmo quando a situação envolve uma única voz, o som é coordenado com as características do ambiente circundante; particularmente quando os Kaluli cantam durante o trabalho" (Feld, 1984, p. 393). De forma similar, os sujeitos presentes na Praça Sete ajustam os sons que emitem entre si. A textura superposta resultante também aponta para uma polifonia vocal coordenada, similar em estrutura, mas em diferentes condições, para as canções cerimoniais do povo da Papua Nova Guiné. Cada som no quarteirão parece sintonizar-se na medida em que se encaixam uns nos outros, manipulados em sua frequência e intensidade por seus usuários, a fim de dividir o espaço.

A Praça Sete encontra-se na fronteira de zonas comerciais populares 
e mais elitizadas. Em alguns de seus bancos, pessoas permanecem sentadas, conversando uma linguagem repleta de gírias incompreensíveis e carregando bolsas com diferentes tipos de objetos, aparentemente roubados. As negociações comerciais nas lojas transformam-se em negociação de espaço nas calçadas. Durante trabalho de campo ${ }^{6}$ uma das pesquisadoras viu, por volta das 8 horas da manhã, uma loja de discos que abria, enquanto pessoas sem teto que costumam dormir na praça acordavam. A loja (figura 3) tocava boleros, que se espalhavam pela calçada, devido às caixas de som posicionadas na porta, enquanto os sem teto batucavam nos bancos um ritmo de samba. A insistência na performance fez com que os vendedores da loja mudassem o disco que tocavam para um de samba, sintonizando a loja com os moradores de rua, que demonstraram satisfação, quando viram seus ritmos entrelaçarem-se com os do estabelecimento. $\mathrm{O}$ que era previamente "um fluxo musical [...] estabelecido por meio da compatibilidade e entrecruzamento de canções a fim de fazer com que todas as transições de canção a canção sejam sem emendas" (Sterne, 1997, p. 32) abruptamente se transforma em "formas de administrar diferenças espaciais [...] intimamente ligadas à administração de diferenças sociais" (Sterne, 1997, p. 41).

Fig. 3: Fachada de loja de discos na Praça Sete, 13 de março de 2013.

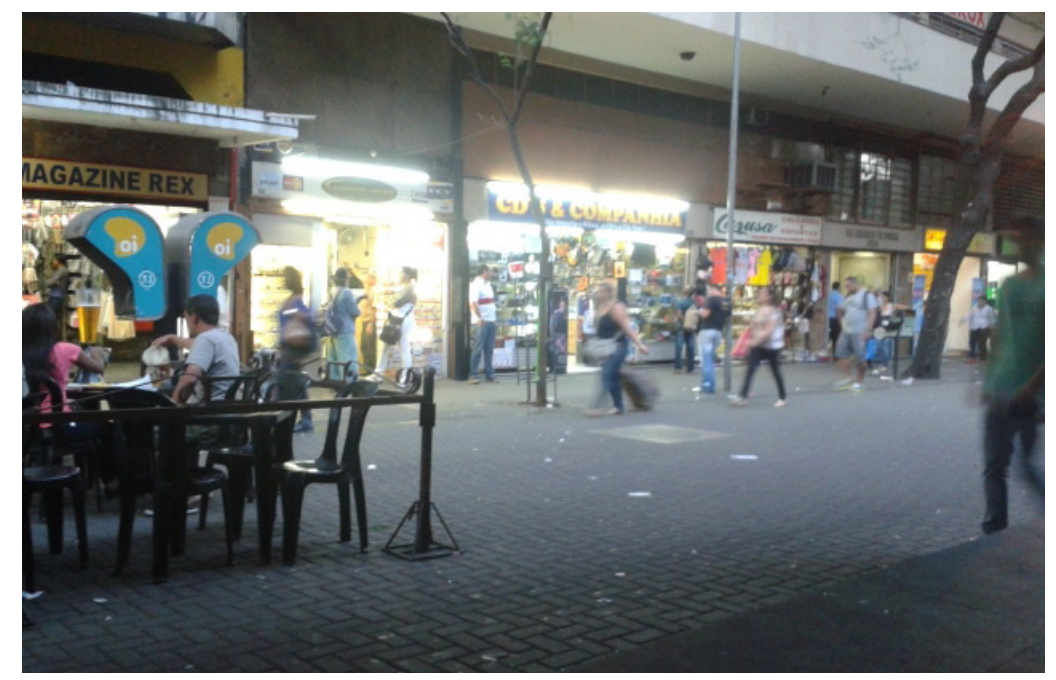

Foto: Maíra Oliveira.

Esta forma de interação também pode ser encontrada em outro

6 Cláudia Graça da Fonseca. Relato de campo. Praça Sete. Belo Horizonte, 24 de abril de 2014. 1p. 
calçadão da praça, onde um dos prédios ${ }^{7}$ é ocupado sobretudo por lojas que vendem discos de rock, punk, heavy metal, mas também instrumentos, roupas relacionadas a estes gêneros musicais e equipamentos para a prática de skate. $\mathrm{O}$ som das manobras de skate e das pequenas rodas rolando na calçada também pode ser ouvido durante algumas horas do dia (usualmente ao fim da tarde e começo da noite). Sintonizando-se a esta "tônica rebelde", encontramos protestos que usualmente acontecem neste calçadão. Eles acontecem em horários determinados, usualmente ao meio dia, ou final da tarde, com carros equipados com caixas de som que podem ser escutados há quase dois quarteirões de distância, como algumas gravações do grupo mostram. Aqui, o som intenso, muitas vezes cançonetas de protesto compostas pelos próprios movimentos sociais, é usado como manifestação de poder, desafiando o ruído sagrado (Schaefer, 2001) do engarrafamento, espalhando mensagens dos trabalhadores em greve e outros movimentos sociais em favor de causas como melhor transporte público, casas para sem teto, etc. Ao fazê-lo, manipulam a intensidade, a fim de disputar o espaço da praça e tomar posse dele.

Um último exemplo nos ajuda a compreender esta dinâmica. Toda sexta-feira, um restaurante no mesmo calçadão onde os skatistas treinam suas manobras transforma o passeio em um bar, colocando mesas e cadeiras em sua frente e servindo cerveja aos clientes. Um músico toca canções populares brasileiras no violão e canta, estabelecendo uma ambiência para os clientes conversarem uns com os outros, como discutimos alhures (Garcia; Marra, 2012). Era cerca de 7 horas da noite, quando gravamos ${ }^{8}$ o músico tocando seu repertório. Ao fundo, é possível escutar o som de skates tocando o chão, após um salto. Nem a música nem o barulho da prática esportiva impediram a diversão de quem se sentava nas mesas.

No que diz respeito às dinâmicas de construção social da Praça Sete, percebemos que as práticas que intencionam se fixar aí devem lidar com o compartilhamento do espaço. O lugar é ocupado por uma grande diversidade de pessoas e grupos, o que torna difícil, na maioria das vezes, conquistá-lo por um longo tempo: ainda que agentes de maior poder econômico ou político

7 Galeria Praça Sete, também conhecida como Galeria do Rock.

8 Pedro Silva Marra. Gravação de campo. Praça Sete. Belo Horizonte, 20 de dezembro de 2014. 
consigam imprimir no espaço mudanças mais permanentes e práticas periódicas, encontramos ali uma proliferação de ocupações populares igualmente cíclicas e recorrentes, que adotam as dinâmicas de táticas e de contra-usos delineadas por Certeau (1994). A solução para este dilema é encontrar formas de vivê-lo em conjunto com outras formas de ocupação do lugar. Labelle, escrevendo acerca do Muzak e da música ambiente em Shopping Centers, advoga que "ao introduzir ambiguidade na equação, e deixar o ouvido escutar errado, espero realçar a música de fundo como uma das várias experiências auditivas a partir das quais nós ainda podemos aprender a escutar" (Labelle, 2010, p. 200). Escutar a Praça Sete corretamente é escutar seu fundo sobreposto, a fim de entender a ambiguidade e aleatoriedade introduzida pela polifonia que Ihe habita, para que se consiga inserir seu próprio som na sonoridade da praça.

Assim, mais do que uma escuta distraída, pensamos que estes casos aqui narrados relacionam-se a outro plano de atenção corporificada, muitas vezes "não proposital, não cognitiva, orientação e expectativa animalesca com relação ao ambiente físico" (DeNora, 2004, p. 84). Estas dinâmicas apontam para um aspecto estético do cotidiano, já que se torna necessário aos habitantes da cidade desenvolver uma sensibilidade auditiva que percebe e distingue as sonoridades momentaneamente presentes no espaço, para que se torne possível julgar, às vezes em um átimo de segundo, a decisão mais adequada para atingir o objetivo de também inscrever-se sonoramente no lugar. Para adquirir tais habilidades, torna-se necessário que os cidadãos alcancem uma sintonia fina com o ambiente - muitas vezes desenvolvida a partir do longo tempo que passam nestes locais - no qual sua atenção sincroniza-se ao "aparecimento de algo que está aparecendo" formulando uma percepção estética que "ancora a consciência (que é muito receptiva a abstrações, antecipações e retrospectivas) através de períodos de um intenso apelo à presença" (Seel, 2014, p. 26-27).

\section{Som, música popular e divisão do espaço na Praça da Savassi}

A Praça Diogo de Vasconcelos, demarcada pela interseção das avenidas Getúlio Vargas e Cristóvão Colombo, é mais conhecida como Praça da Savassi. Em uma das esquinas, no início da década de 1940, inaugurou-se uma padaria que recebeu o sobrenome de seus proprietários. O bairro dos Funcionários, de caráter 
eminentemente residencial, foi se transformando em região de consumo das camadas médias e altas em busca de lojas sofisticadas, processo intensificado na década de 1970 (Lemos, 2007). A tais atividades articulavam-se formas de lazer e sociabilidade que correspondiam às expectativas destes frequentadores. Não por acaso surgiu ali nos, anos 1980, a livraria Agência Status, em frente ao principal ponto de ônibus na Av. Cristóvão Colombo, do lado oposto em que estava o Cine Pathé, já então consagrado como ponto de encontro de intelectuais, associado ao "filme de autor". Podemos considerar que na década de 1990 o cenário da praça tornou-se mais complexo e heterogêneo. A grande quantidade de linhas de ônibus que trafega e para nos pontos das avenidas que nela se entrecruzam, a existência de algumas lojas e lanchonetes de preço acessível, a diversificação de serviços e eventualmente a própria centralidade que passou a exercer, aumentou significativamente a afluência e variedade das pessoas que circula e se apropria do espaço.

A última reforma foi realizada entre março de 2011 e maio de 2012 custou, segundo informações colhidas pela imprensa junto à Prefeitura Municipal de Belo Horizonte (PBH), entre 10,4 e 11,8 milhões de reais (Nova, 2012; Hemerson; Holanda, 2012) e sinaliza a tentativa de ajustar a fisionomia da praça a um projeto "enobrecido", com a intenção de selecionar socialmente o público destinado a frequentá-la. Porém, se a regulação dos padrões de apresentação das lojas, instalação de um mobiliário urbano padronizado nos quarteirões fechados, adicionado à elevação do custo para o funcionamento dos estabelecimentos sinaliza esta intenção, grupos "indesejáveis" ainda marcam sua presença assinalando uma disputa, ainda que desigual, pelo espaço da praça. Assim, a Praça da Savassi testemunha em tantas mudanças e embates a voragem de nosso tempo, e como aponta Andreas Huyssen, "as fantasias da globalização dos 1990 já se tornaram em si parte do arquivo da memória e dos seus armários de desilusão." (2003, p. 6).

Cada quarteirão tem sua configuração própria, e tem sua rotina diária condicionada pelas atividades e usos desempenhados por quem mora, trabalha ou passa por eles (figura 4). Nossas incursões visaram captar a produção e organização do espaço e da paisagem sonora a partir de parâmetros de intensidade, frequência e espacialidade. Um relato deste tipo de caminhada é como o seguinte: 
Passo ao quarteirão em que fica a Elmo (Rua Pernambuco). Um violinista toca bem em frente à tradicional loja de calçados, uma das que está há mais tempo na Savassi. [...] Poucas pessoas estão sentadas nos bancos da borda e igualmente nos que ficam na parte mais alta do quarteirão. Em geral acredito que o desenho desses bancos no interior dos quarteirões não favorece longas permanências. Os bancos de pedra, especialmente sob as sombras, são bem mais convidativos. As mesas do Ateliê (antiga Travessa) estão pouco ocupadas. Aqui, como no Café 3 Corações, as pessoas se reúnem a trabalho, com notebooks abertos sobre as mesas. Do som do restaurante ouço, ainda que mal, uma canção de Chico Buarque. Toca Ensaio Geral e depois As vitrines - notável que sejam canções que remetem diretamente ao espaço urbano 9 .

Fig. 4: Mapa síntese da ocupação da Praça da Savassi

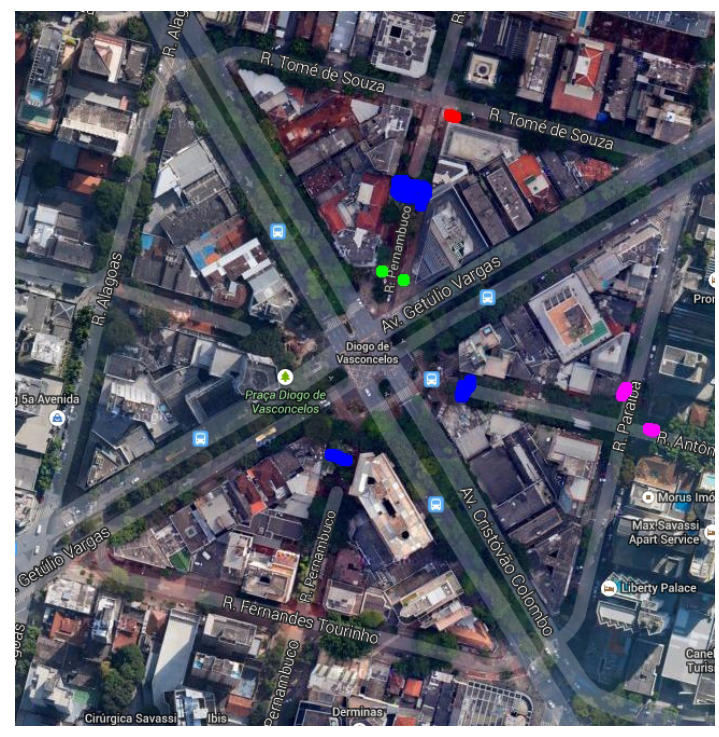

Vermelho: Padaria com caixa de som na marquise

- Rosa: Bares com caixa acústica no chão

- Azul Escuro: Ocupação de bares e cafés com música ao vivo

- Verde: Zona de limiaridade

Fonte: Mapa extraído do Google Maps e alterado digitalmente pela pesquisa, 29/05/2014.

Em muitas ocasiões seguimos um roteiro específico sain do da Rua Paraíba, por dentro do quarteirão fechado em direção à av. Getúlio Vargas, atravessando

9 Luiz Henrique Assis Garcia. Relato de campo. Praça da Savassi. Belo Horizonte, 18 de março de 2014. $1 \mathrm{p.}$ 
para o quarteirão da Rua Pernambuco até a esquina com Tomé de Souza. Nessa rota é possível perceber como os bares e cafés usam o posicionamento das caixas de som para provocar certo tipo de ambiência (figura 5). Quando estão posicionadas no alto criam ambientes para a conversa, que não entram em conflito com o espaço do estabelecimento vizinho. Em bares onde as caixas estão no chão, o som é mais alto, provocando a necessidade de aumentar a intensidade da conversa. Essa interferência sonora mais ostensiva (tentativa de transformar a rua em boate?) indica a intenção de demarcar uma divisão quase institucionalizada do espaço da calçada. Essa demarcação também lança mão das preferências musicais associados ao perfil de público que os bares atraem e com o qual procuram se identificar no cardápio, na decoração e nas formas de sociabilidade que promovem. Assim, temos um repertório de hard rock tocando sem parar no Vintage 13 pub, ponto de encontro de aficionados por motocicletas, e DJs tocando música pulsante no Anos 80, com constantes referências ao repertório de danceteria da década que consta no nome do bar.

Fig. 5: Detalhe da caixa de som tocando pagode posicionada no alto, na lanchonete/sorveteria Yoggi, próxima à Status, 21 de março de 2014.

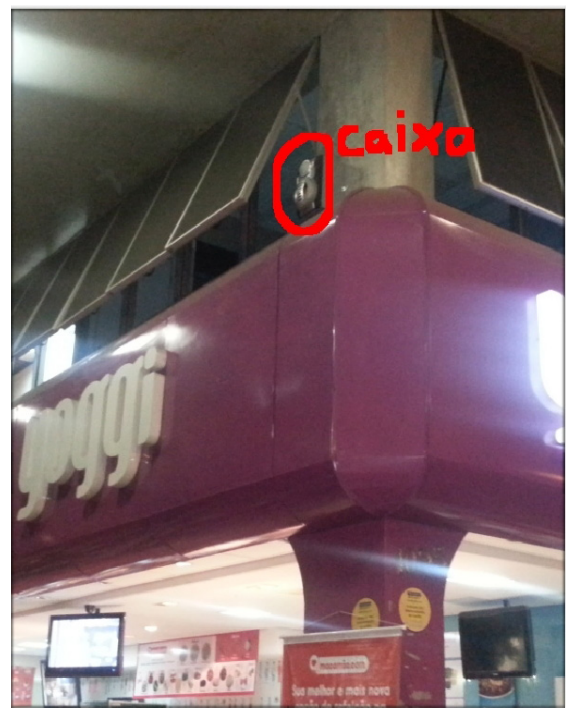

Foto: Luiz Henrique Assis Garcia.

Nas execuções ao vivo podemos determinar como gêneros predominantes o rock, a bossa-nova e o repertório de voz e violão típico de MPB mesclado a canções jazzy, bluesy, ou de sabor pop. No Ateliê apresenta- 
se semanalmente um duo com cantora (voz e violão) e instrumentista (baixo), cujo repertório, segundo a própria definiu, inclui MPB, Pop, xote, etc., reunido numa "roupagem própria" (os arranjos de autoria do duo) ${ }^{10}$. Na Status, bandas de rock predominam, mas também se apresentam conjuntos de jazz, incluindo aí instrumentistas importantes da cena local, crooners e cantoras com repertório básico (e "manjado") da bossa-nova, com algumas pinceladas MPB. Vale notar que os palcos de show estão estrategicamente localizados para que uma apresentação não concorra com outra. Quando acontece uma apresentação com maior intensidade, em palcos maiores que são montados mais próximos das avenidas, os shows sincronizam-se e os músicos aguardam pelo término do espetáculo mais ruidoso. Como vemos, é justamente o hábil ajuste dos parâmetros que indicamos que faculta a estabelecimentos ou organizadores de eventos afetar o espaço através do som, em seus aspectos materiais e intangíveis.

A reforma da praça participou desse jogo, ao modificar o espaço, fechando quarteirões e estabelecendo um novo mobiliário urbano. Mas as estruturas que propôs também foram apropriadas, para além do projeto. Deve notar-se que os quarteirões fechados proporcionam uma acústica adequada da forma como configuram lacunas entre duas fileiras de edifícios que não são altos, mas atuam como paredes. Os bares ou cafés que promovem apresentações de música ao vivo aproveitam-se dessa arquitetura, posicionando palcos improvisados e equipamentos de som dos músicos de costas para as avenidas e para o interior das ruas fechadas, onde estão posicionadas as suas mesas e cadeiras dobráveis. Percebemos, por um lado, um esforço para demarcar os limites da propriedade - o que amplia para o espaço da rua a fronteira do bar e reproduz, portanto, a lógica privada dos espaços comerciais - e marcar o perfil do público que se sentam em suas mesas para comer enquanto conversa e ouve música, e, do outro lado, uma série de práticas que desafiam ou tentam adaptar-se aos limites impostos. O caso da Status parece particularmente significativo:

10 Num dos campos (02/05/2014) o repertório incluía Fascinação (F. D. Marchetti/Maurice de Féraudy, versão de Armando Louzada, muito conhecida na gravação de Elis Regina), Mais que nada (Jorge Ben), Back to Black (Winehouse/Ronson) e Morena tropicana (Alceu Valença). Em outro dia (09/05/2014), Burguesinha (Seu Jorge), Ando meio desligado (Arnaldo Baptista, Rita Lee \& Sérgio Dias - Mutantes), Pagu (Rita Lee, e repertório de Maria Rita). 
As divisórias ostensivas de fato reforçam a divisão que de alguma forma já opera ali no quarteirão fechado da Status e do McDonald's. Os meninos pobres, catadores, moradores de rua, hippies e pedintes ficavam nas margens, embora por vezes se aventurassem em passar entre as mesas e pessoas que estavam em pé na área delimitada por elas em frente aos bares. Em geral para pedir dinheiro ou catar latinhas. Um deles interagiu comigo, um senhor que carregava um saco de lixo nas costas, mas não catava nada. Bebia uma cerveja e ofereceu colocar um pouco no meu copo, mas neste havia pequenos churros que comprara no Fujiama, na esquina seguinte à do quarteirão fechado. Ofereci e ele aceitou um, trocamos sorrisos, e ele seguiu passando no meio das pessoas. Em outro momento, enquanto uma das bandas (Nélson e os Besouros - RS) tocava Twist and Shout, passou por mim um adolescente, descalço, sujo e maltrapilho, tentando acompanhar a canção num "falso inglês" como aquele que utilizam os lavadores de carro "otcheiquirobeibe/ pissensau...[well, shake it up, baby/twist andshout]" e coisas do tipo. ${ }^{11}$

A atividade de catar latinhas assinala uma liminaridade aí, na medida em que as latas são simultaneamente o resto do consumo dos clientes do bar e o ganha pão dos catadores (figura 6). 0 'falso inglês' por sua vez representa um marcador de diferença. A apropriação realizada pelo jovem que passou por mim demarca a tensão entre o inglês globalizado que circula através de uma canção muito veiculada pela indústria cultural e sua forma "localizada"em que se guarda a sonoridade mas se impõe uma dicção abrasileirada. Ao cantá-la desse modo o rapaz não deixa de assinalar que encontra uma forma de integrar o fluxo global do qual a canção participa, ao mesmo tempo em que se encontra desprovido do capital cultural/social que o habilitaria a estudar inglês regularmente para apropriar-se com precisão do que está cantando. Usamos "localidade" aqui como categoria relacional e contextual, "[...] constituída por uma série de elos entre o sentido de imediaticidade social, as tecnologias de interatividade e a relatividade dos contextos" (Appadurai, 1996, p.178). Neste sentido, ao apropriarse e "transcultural" em seu contexto o que emite a aparelhagem de som, esse sujeito participa da produção espacial da "localidade" (Appadurai, 1996, p.179).

11 Luiz Henrique Assis Garcia. A. Relato de campo, durante a BH Beatle Week. Praça da Savassi. Belo Horizonte, 14 de dezembro de 2013. 1 p. 
Fig. 6: Público nas mesas da Status durante a BH BeatleWeek, com palco ao fundo; Plano mais próximo da borda do quarteirão fechado, mostrando artesãs e ambulantes nos bancos de pedra, 14 de dezembro de 2013. Detalhe para as grades de separação em $2^{\circ}$ plano.
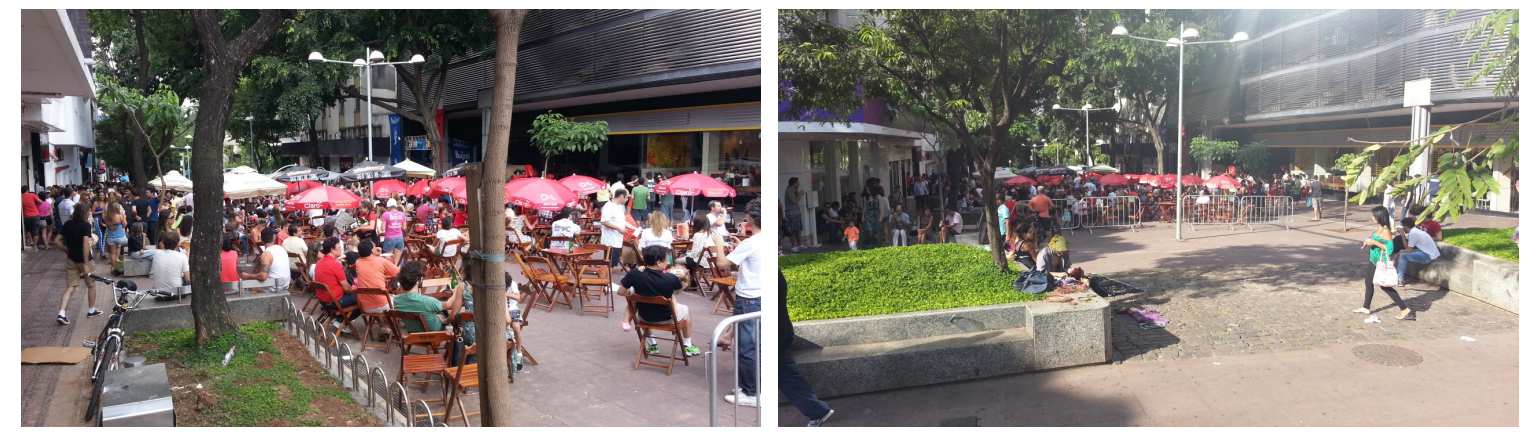

Fotos: Luiz Henrique Assis Garcia

Interessante observar também os diferentes comportamentos dos que estão sentados nos bares em que se apresentam músicos. Uma parte fica sentada voltada para o palco, configurando uma efetiva audiência, outra de costas ou de lado mantendo uma atitude basicamente de indiferença, a não ser nos finais das músicas quando alguns batem palmas mecanicamente. A fruição das apresentações, para alguns, é claramente mediada pela perspectiva do consumo:

[...] as figuras, sentadas na mesa da Status logo em frente ao palco, depois de se esbaldar em comes e bebes, que lá não são baratos, questionavam o garçom por conta do couvert artístico, pois este os informara que deviam pagar $\mathrm{R} \$ 20,00$ por cabeça. Eles alegavam que não tinham sido informados e queriam pagar 20 pela mesa toda. E ainda retrucavam que o Aggeu [músico e organizador das apresentações] tinha acabado de alardear no microfone que o evento é sem patrocínio e as bandas não iam receber cachê. Para além do fato que muitos desconhecem o mecanismo de extorsão por trás do couvert, é triste constatar que a maioria não contesta o preço exorbitante dos alimentos do corpo, mas está sempre disposto a reclamar muito pelos alimentos da alma. ${ }^{12}$

Numa das passagens em campo reparamos no comportamento diferente de um morador de rua que, de pé bem próximo ao palco, acompanhava com o corpo a apresentação de um trio (baixo, bateria, teclado), tocando ele próprio

12 Luiz Henrique Assis Garcia. A. Relato de campo. Praça da Savassi. Belo Horizonte, 14 de dezembro de 2013. 1p. 
no ar alternadamente um teclado e uma guitarra "imaginários"13. Visivelmente em seu próprio mundo aparte, ninguém o molestou, provavelmente porque, de algum modo, ele penetrou a divisória sem fazer com que sua presença fosse incômoda. Mas os "indesejáveis" podem desencadear conflitos. Registramos um episódio interessante e revelador em 16 de abril de 2014, quando músicos ambulantes sul-americanos ${ }^{14}$, avançaram para a área cercada da Status e tocaram perto de algumas mesas.

Receberam alguns aplausos de quem estava sentado nelas, mas "depois de encerrarem o garçom se aproxima e conversa. Pelos seus gestos eu deduzo que está falando para os músicos não tocarem mais aqui"15. Alguns dias antes eles haviam se apresentado no palco, porém é possível que tal atração 'exótica' não seja considerada para várias apresentações. Tais relatos evidenciam não só a tomada de posse do lugar por práticas econômicas mais formais e estabelecidas, mas também sua relação ambígua com seus vizinhos informais ou com aqueles que sobrevivem dos restos e desperdícios do capitalismo. 0 músico de rua é aceito quando toca no palco e com isso contribui com a mais valia dos consumidores, mas não quando circula entre os clientes de maneira independente. O morador de rua - a quem se atribui pequenos furtos, ou que molesta os clientes com pedidos de esmola - é considerado indesejado, a não ser que se mantenha absorto em seu próprio mundo. Tentar retirá-lo do local poderia reconectá-lo no mundo compartilhado com os cidadãos consumidores, o que o recolocaria no lugar do pedinte a importunar a clientela com suas súplicas de caridade.

Constatamos que o espaço da Praça da Savassi revela um loteamento sonoro mais bem delimitado, especialmente nos quarteirões fechados, a despeito de ocorrerem por vezes penetrações como as que indicamos nos relatos, que propriamente revelam conflitos sociais e simbólicos extremamente assimétricos que são historicamente significativos em termos das sociabilidades e da fisionomia urbana da praça. Em muitos trabalhos em campo nossos registros de áudio assemelham-se ao ato de girar o dial de um rádio, enquanto

13 Luiz Henrique Assis Garcia. A. Relato de campo. Praça da Savassi. Belo Horizonte, 20 de maio de 2014.

14 Com a aproximação da Copa do Mundo, a sua presença estava aumentando na cidade.

15 Luiz Henrique Assis Garcia. A. Relato de campo. Praça da Savassi. Belo Horizonte, 16 de abril de 2014, 1 p. 
vamos percorrendo as ruas, dobrando esquinas e alternando ambiências. A exceção à regra vem sendo a realização de espetáculos mais massificados (cujas amostras recentes foram os shows realizados durante a Copa do Mundo 2014 e no Carnaval em fevereiro 2015) em que a afluência de um público diverso e numeroso combina-se com emissões de grande intensidade produzindo efeito de sobreposição e mesmo 'borra' sobre a configuração rotineira da paisagem sonora local. Intervêm aí fluxos de capital transnacional ligados a dinâmica dos Mega Eventos, ou dinâmicas políticas locais com a intenção de trazer para junto de políticos e governantes em exercício certas manifestações culturais populares que em princípio se contrapunham discursivamente à administração pública. No geral, os procedimentos de discotecagem mostram-se bastante elaborados, inclusive na maneira como estão adaptados à materialidade do espaço da praça.

\section{Considerações finais}

Mostramos como através do uso de som e da música popular os habitantes da cidade delineam diferentes práticas para partilhar, disputar e dividir o espaço em duas praças de Belo Horizonte. Para tanto, eles manipulam os sons, como tecnologias de ordenação social (DeNora, 2004), negociando lugar. Demonstramos ainda como o repertório musical é posto em ação (Faulkner; Becker, 2009) pelas escolhas de canções tocadas por músicos, DJs e lojas, para conquistar o espaço, "discotecando" a sonoridade do lugar, e colocando estrategicamente alto-falantes para construir fronteiras invisíveis, mas estáveis, no território. $O$ estudo desses fenômenos representa relevante demonstração de como as tecnologias da comunicação são empregados nos embates pelo espaço urbano.

\section{REFERÊNCIAS}

APPADURAI, Arjun. Modernity at large: cultural dimensions of globalization. Minneapolis: University of Minnesotta Press,1996.

CERTEAU, Michel De. A invenção do cotidiano. Petrópolis: Editora Vozes, 1994.

DENORA, Tia. Music in Everyday Life. Cambridge: Cambridge Univerity Press, 2004. 
FAULKNER, Robert; BECKER, Howard. Do you know...? The Jazz Repertoire in Action. Chicago: University of Chicago Press, 2009.

FELD, Steven. Sound Structure as Social Structure. In: Ethnolusicology, v.28, n.3, p. 383-409, sep. 1984.

FRANCO, Juliana; MARRA, Pedro. Som e complexidade urbana: apontamentos a partir de uma visao sistêmica das sonoridades do comércio popular no Hipercentro de Belo Horizonte. Ciberlegenda, 24(2), 2011, p. 146-159.

HAESBAERT, Rogério. Territórios Alternativos. Contexto, São Paulo, 2006.

HAESBAERT, Rogério; LIMONAD, Ester. O território em tempos de globalização. In Etc ... espaço, tempo e crítica - Revista Eletrônica Científica de Ciências Humanas e Sociais e outras coisas. v.1, n.2, ago. 2007, p. 39-52.

HEMERSON, Landercy; HOLANDA, Tiago de. Revitalização: enfim, a Savassi ficou pronta. Estado de Minas (on-line), 09/05/2012. Disponível em: <http://www.em.com. br/app/noticia/gerais/2012/05/09/interna gerais,293242/revitalizacao-enfima-savassi-ficou-pronta.shtml>. Acesso em: 29 mai. 2014.

HUYSSEN, Andreas. Present Pasts: Urban Palimpsests and the Politics of Memory. Stanford University Press, 2003.

IDHE, Don. Listening and Voice: Phenomenologies of Sound. New York: State University of New York Press, 2007.

GARCIA, Luiz Henrique; MARRA, Pedro. Ouvir música na cidade: experiência auditiva na paisagem sonora urbana do hipercentro de Belo Horizonte. Revista Contemporânea UERJ, 10, 2012, p. 43-57.

LABELLE, Brian. Acoustic Territories: sound Culture and everyday life. London: Continuun International Publishing Group, 2010.

LEFEBVRE, Henry. Rhythmanalysis: Space, Time and Everyday Life. New York: Continuun, 2004.

LEMOS, Celina. A formação da Savassi como uma centralidade belo-horizontina: a cultura do consumo, passagens e territorialidades. In: XII ANPUR, 2007, Belém. Anais do XII Encontro da Associação Nacional de Pós-Graduação e Pesquisa em Planejamento Urbano e Regional, Belém, 2007, p. 1-21.

LOW, Setha M. Spatializing Culture: The Social Construction of Public Space in Costa Rica. In Theorizing the City: The New Urban Anthropology Reader. New Jersey: Rutgers University Press, 1999, p. 111-137.

MARICATO Ermínia. A cidade do pensamento único. Vozes, Petrópolis, 2000.

NOVA Praça da Savassi é inaugurada em Belo Horizonte. Portal G1, 10/05/2012. 
<http://g1.globo.com/minas-gerais/noticia/2012/05/nova-praca-da-savassi-einaugurada-em-belo-horizonte.html>. Acesso em: 29 mai. 2014.

SANTOS, Milton. A natureza do espaço: Técnica e tempo. Razão e emoção. Editora Hucitec, São Paulo, 1996.

SAKAKEENY, Matt. Resounding Silence in the Streets of a Musical City. In: Space and Culture, v.9, n.1, p. 41-44, feb. 2006.

SEEL, Martin. No escopo da experiência estética. In PICADO, Benjamin; MENDONÇA, Carlos Magno Camargos; FILHO, Jorge Cardoso. Experiência Estética e Performance. Salvador: EDUFBA, 2014.

SCHAFER, Murray. A afinação do mundo: uma exploração pioneira pela história e pelo atual estado do mais negligenciado aspecto do nosso ambiente: a paisagem sonora. São Paulo: UNESP, 2001.

STERNE, Jonathan. Sounds like the Mall of America: Programmed Music and the Architectonics of Commercial space. In Ethnomusicology, v.41, n.1, p. 22-50, Winter, 1997.

THIBAUD, Jean-Paul. A sonic paradigm of urban ambiances? Journal of Sonic Studies, v.1, n.1, p. 1-14, 2011.

THOMPSON, Marie; BIDDLE, Ian. Sound, Music, Affect. Nova lorque: Bloomsbury, 2013.

TUAN, Yi-Fu. Espaço e lugar: a perspectiva da experiência. São Paulo: Difel, 1983.

WISNIK, José Miguel. O som e o sentido: uma outra história das músicas. São Paulo: Companhia das Letras, 1989. 